\title{
New Design Tools for Lightweight Aerospace Structures
}

\author{
Raimund Rolfes ${ }^{1}$, Jan Tessmer $^{1}$, Richard Degenhardt ${ }^{1}$, Hubert Temmen ${ }^{1}$, \\ Philipp Bürmann ${ }^{1}$, Janos Juhasz ${ }^{2}$ \\ ${ }^{1}$ DLR, Institute of Structural Mechanics, Braunschweig, Germany \\ ${ }^{2}$ Docter Optics, Neustadt/Orla, Germany
}

\begin{abstract}
This paper presents two new design tools for lightweight aerospace structures. The first tool is the Tailored Fibre Placement (TFP) design tool TACO. It is used to optimize the fibre orientations of structures made of Carbon Fibre Reinforcement Plastics (CFRP). The optimization concept is explained and results are given for a horizontal tail plane connection beam of an aircraft. The second tool, iBuck, is a fast, semi-analytical local buckling and post-buckling tool for stiffened panels that are loaded in-plane. The panels are assumed to be representative for an aircraft fuselage and are stiffened in axial and circumferential direction. Results are presented for axially loaded panels and compared to FE-results.
\end{abstract}

Keywords: optimization tools, tailored fibre placement, composites, HTPconnection beam, local buckling, stiffened panel, post-buckling, curved shells

\section{Tailored Fibre Placement Optimization Tool}

\subsection{Introduction}

Tailored Fibre Placement (TFP) is a textile process for the production of fibre reinforced structures. Using TFP the carbon fibre rovings may be placed on a base material in almost any desired orientation, thus deploying calculated optimum fibre quantities and orientations for optimal performance. In common composite structures the anisotropic material properties are usually not fully exploited.

In Figure 1.1 it is illustrated how the relative strength of a composite layer depends on the angle $\alpha$ between the fibre (within that layer) and the load direction. In this simple example, only axial tension and compression is considered. If the direction of the load is only 10 degrees off the fibre direction, its load-carrying 
capacity is reduced by $80 \%$. It is thus plausible that the weight of composite structures could be significantly reduced if the fibres were fully exploited. In the simple example from Figure 1.1 the optimal fibre orientation would be at $\mapsto=0$. However, in a real structure under different loading conditions there may exist different solutions for each load case. It is therefore expected that the optimization potential is especially high, if only a few load cases need to be considered.

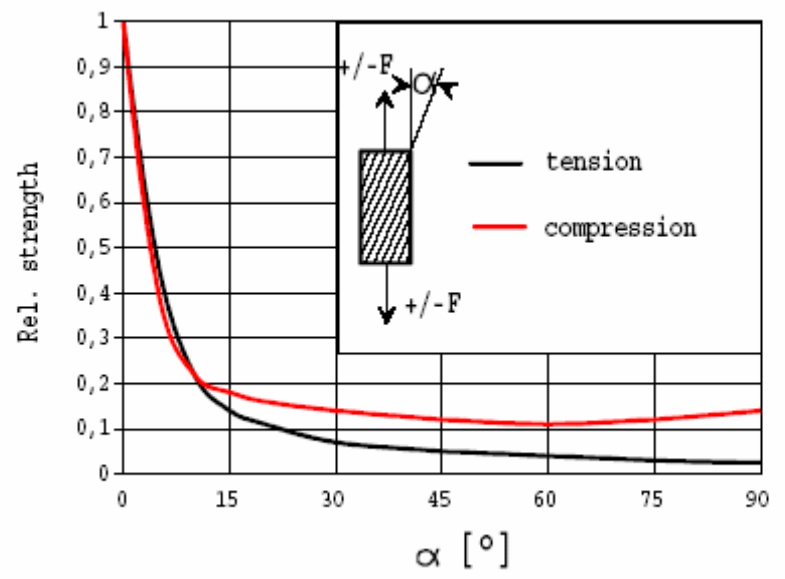

Figure 1.1: Dependence of relative strength and angle between fibre direction and load direction [1]

Stress concentration at notches, edges and cut-outs are critical in view of the material failure behaviour in a structure. While in isotropic structures only a shape optimization is possible to reduce local stress concentrations, in orthotropic and composite structures an orientation of the fibres appropriate to the local stress condition can be used as an additional local design variable for strength and stiffness optimization.

In the CAIO method $[9,10,14]$, a procedure to optimize fibre arrangement in composite structures, the fibres of a loaded structure are locally aligned to the principal directions of the stresses. Since stress distribution and fibre orientation are coupled, an iterative procedure is necessary to align fibre orientation in the principle direction of the stress. As result of this procedure the shear stress and the corresponding failure response is reduced.

Using an optimization criterion in combination with FEM provides a very efficient optimization method leading to a curvilinear fibre pattern in contrast to the constant fibre direction of traditional design [4-6, 8-16]. The application of such a procedure allows an optimized design for a specific composite light-weightcomponent. It aims to fully exploit the uniaxial material properties, leads to a local reinforcement and a more efficient load transfer and improves the fracture behaviour. Main area of application are uniaxial loaded laminate structures with a 
limited number of load cases. A typical application is an open-hole plate under unidirectional tensile loading.

In $[12,17]$ it is pointed out how the manufacturing process affects the material properties. For example, in [12] the influence of stitching on fracture behaviour is considered in TFP structures. A challenging problem in the analysis of the anisotropic mechanical properties of composites has been the development of adequate failure criteria. A strength model for 3D fiber-reinforced plastics consisting of unidirectional layers with a high in-plane fiber density and additional reinforcements perpendicular to the layers with a significantly lower fiber density is presented in [19].

The tool TACO (Tailored Composite Design Code) was developed to optimize complex composite structures and it is embedded in the MSC PATRAN / NASTRAN environment. An optimization criterion instead of a mathematical optimization is used, because in the mathematical approach the number of design variables becomes too large. As optimization criterion the two-dimensional CAIO formulation was adapted. The tool changes the fibre orientations within a userdefined layer of a finite-element (FE) model such that the fibres are as closely aligned to the direction of the principal stresses as possible. For failure analysis the so called Simple Parabolic Criterion (SPC) was implemented (cf. Section 1.3), which is able to distinguish between fibre fracture and inter fibre fracture as different failure modes.

An effective method to calculate the 3D stress state using only 2D shell elements was suggested in [18]. In the same way as TACO, this method is implemented in an add-in program for MSC/PATRAN named TRAVEST. In future, combining TRAVEST and TACO with a powerful 3D strength criterion allows for an improved and efficient TFP design even for thicker composite structures.

TACO was applied to optimize a preliminary version of the horizontal tail plane (HTP)-connection beam of an Airbus A340 airplane for which experimental data were available. The HTP-beam was subjected to three independent load cases: tension, combined tension/compression and bending. Three specimens were manufactured at Airbus Germany (plant Stade) according to the optimized solution obtained by TACO and were tested for all three different load cases [2]. The experimental results were compared to the TACO predictions. The results for the optimized HTP-beams were also compared to the results for the conventional composite beams made of fabrics that had been tested earlier.

The first part of this paper aims to demonstrate the TFP capability on the HTPconnection beam as a real industrial structure and aims to show that the structural behaviour is predictable applying the TFP design tool TACO. 


\subsection{Optimization Concept}

Before the optimization procedure starts, a linear plane stress analysis of the structure is carried out. Based on a two-dimensional stress state, the two orthogonal principal directions of the stress

$$
\begin{aligned}
& n^{1}=(\cos \phi, \sin \phi) \\
& n^{2}=(-\sin \phi, \cos \phi)
\end{aligned}
$$

expressed by the angle $\phi$, can be computed from

$$
\tan (2 \phi)=\frac{2 \tau_{x y}}{\sigma_{x}-\sigma_{y}}
$$

The two principal stresses $\sigma_{1}$ and $\sigma_{2}$ are given by

$$
\begin{aligned}
& \sigma_{1}=\frac{\sigma_{x}+\sigma_{y}}{2}+\frac{\sigma_{x}-\sigma_{y}}{2} \cos 2 \phi+\tau_{x y} \sin 2 \phi \\
& \sigma_{2}=\frac{\sigma_{x}+\sigma_{y}}{2}-\frac{\sigma_{x}-\sigma_{y}}{2} \cos 2 \phi-\tau_{x y} \sin 2 \phi
\end{aligned}
$$

The two principal stresses must be compared to decide in which of the two principal directions the fibres should be aligned.

In a simplified method to design TFP structures one starts with a plane stress analysis for a given structure with an arbitrary isotropic material. According to the isotropic stress analysis the fibres are aligned to the direction of principal stresses. In such an approach the coupling of stress state and anisotropy is neglected.

In order to fully exploit the fibres, they are aligned in the direction of the principal stress. However, fibre orientation and stress state are coupled: as the fibre orientation changes, so does the stress state. Thus, another linear plane stress analysis of the structure must be carried out and afterwards it must be checked whether the fibres need to be re-aligned. If so, the process of re-aligning and checking is repeated until convergence is reached. As a result of this procedure the shear stresses becomes small. For the test cases considered in this paper, this only took a few iterations.

\section{Main Subroutines in TACO}

TACO is written in Patran Command Language (PCL) and contains four main subroutines or session files (Properties, Results, Optimization, Failure). A schematic view of the tool and the optimization procedure is given in Figure 1.2. Properties are 
attached to the elements to define fibre orientation for any element. If a FE-model with an appropriate property definition exists and if results of a first stress calculation are given, the optimization procedure can be started. To get all information and settings in a consistent way the sub-routines must be applied in a defined sequence. Applying the subroutines in the described iterative way, results for optimized fibre orientation, stress and strength-analysis are given as result-case in the Patran database.

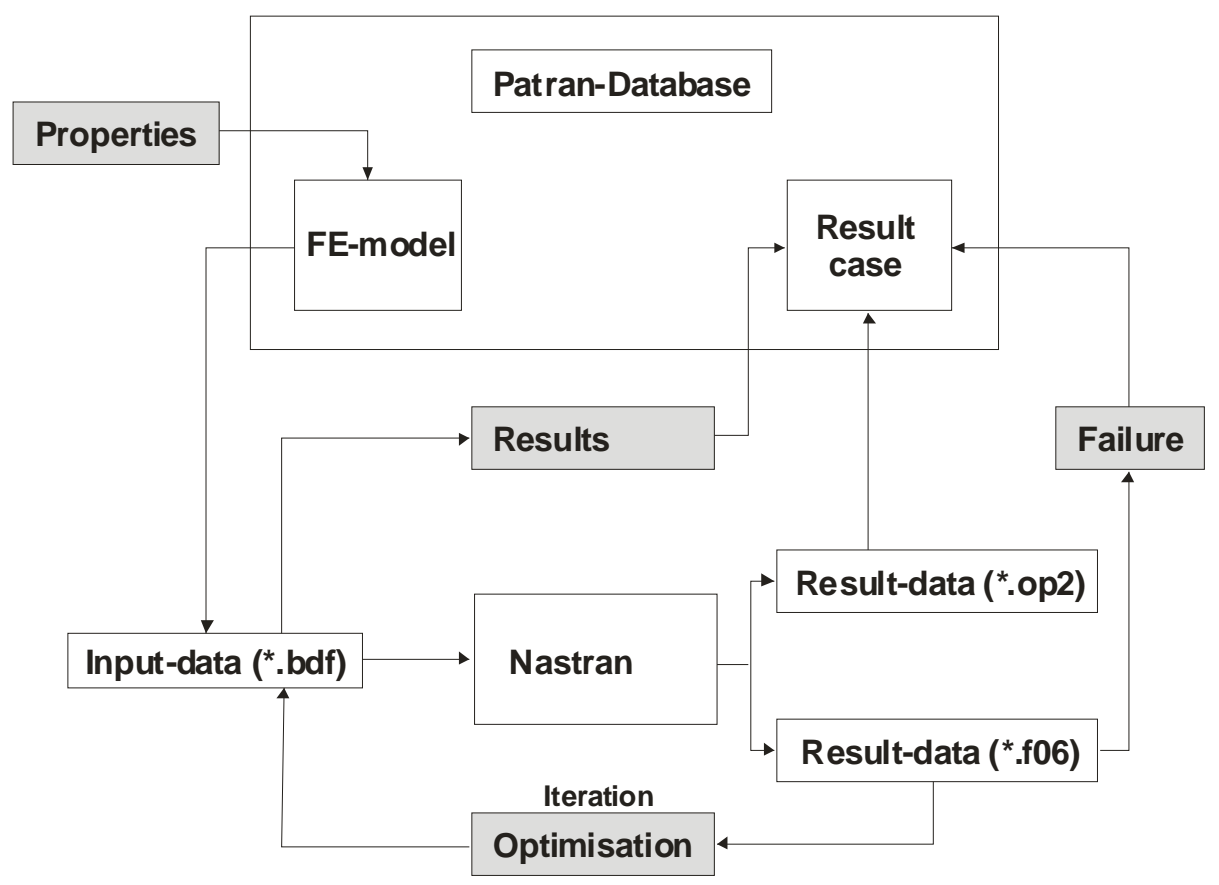

Figure 1.2: TACO Overview

\subsection{Failure Criterion}

In order to optimize the load-carrying capacity of a structure, a criterion for the onset of fracture must be chosen. There are different criteria for the determination of fracture of composite materials. A good overview can be found in Cuntze et al. [3]. For the failure analysis of a TFP-layer, it is recommended to distinguish between Fibre Fracture (FF) and Inter Fibre Fracture (IFF) as different failure modes (cf. $[3,19])$. In the following, these criteria, which are implemented in TACO, are explained.

For FF an appropriate criterion is the simple maximum stress criterion:

$$
\left|\frac{\sigma_{\|}}{\mathrm{R}_{\|}^{(+,-)}}\right|=1
$$


$\sigma_{\|}$is the stress and $\mathrm{R}_{\|}^{(+,-)}$are the strengths of a unidirectional layer for tensile $\left(^{+}\right)$ and compressive (-) loads in fibre direction, respectively. For IFF of unidirectional composite layers a physically based criterion called $\underline{\text { Simple }}$ Parabolic $\underline{\text { Criterion }}$ (SPC) has been developed and experimentally verified by Cuntze et al. [3]. The fracture hypothesis of Mohr for brittle materials is used as a basis. Therefore the criterion is formulated solely in stresses and strengths of the fracture plane (cf. Figure 1.3):

$$
\begin{array}{ll}
\sigma_{\mathrm{N}} \geq 0: & \sqrt{\left(1-\mathrm{p}^{(+)}\right)^{2}\left(\frac{\sigma_{\mathrm{N}}}{\mathrm{R}_{\mathrm{N}}^{(+)}}\right)^{2}+\left(\frac{\tau_{\mathrm{NT}}}{\mathrm{R}_{\mathrm{NT}}}\right)^{2}+\left(\frac{\tau_{\mathrm{NL}}}{\mathrm{R}_{\mathrm{NL}}}\right)^{2}}+\mathrm{p}^{(+)} \frac{\sigma_{\mathrm{N}}}{\mathrm{R}_{\mathrm{N}}^{(+)}}=1 \\
\sigma_{\mathrm{N}}<0: & \sqrt{\left(\mathrm{p}^{(-)}\right)^{2}\left(\frac{\sigma_{\mathrm{N}}}{\mathrm{R}_{\mathrm{y}}^{(-)}}\right)^{2}+\left(\frac{\tau_{\mathrm{NT}}}{\mathrm{R}_{\mathrm{NT}}}\right)^{2}+\left(\frac{\tau_{\mathrm{NL}}}{\mathrm{R}_{\mathrm{NL}}}\right)^{2}}+\mathrm{p}^{(-)} \frac{\sigma_{\mathrm{N}}}{\mathrm{R}_{\mathrm{y}}^{(-)}}=1
\end{array}
$$

$\mathrm{p}^{(+,-)}$represents gradients of the fracture body defined by Equations (1.5) and (1.6). Cuntze et al. [3] developed the following strength model for unidirectional layers using basic strengths of the layer with respect to the material axes:

$$
\begin{aligned}
& \mathrm{R}_{\mathrm{N}}^{(+)}=\mathrm{R}_{\mathrm{y}}^{(+)}=\mathrm{R}_{\mathrm{z}}^{(+)} \\
& \mathrm{R}_{\mathrm{NL}}=\mathrm{R}_{\mathrm{xy}}=\mathrm{R}_{\mathrm{xz}} \\
& \mathrm{R}_{\mathrm{NT}}=\frac{\mathrm{R}_{\mathrm{y}}^{(-)}}{1+\sqrt{1+2 \mathrm{p}^{(-)}}}
\end{aligned}
$$
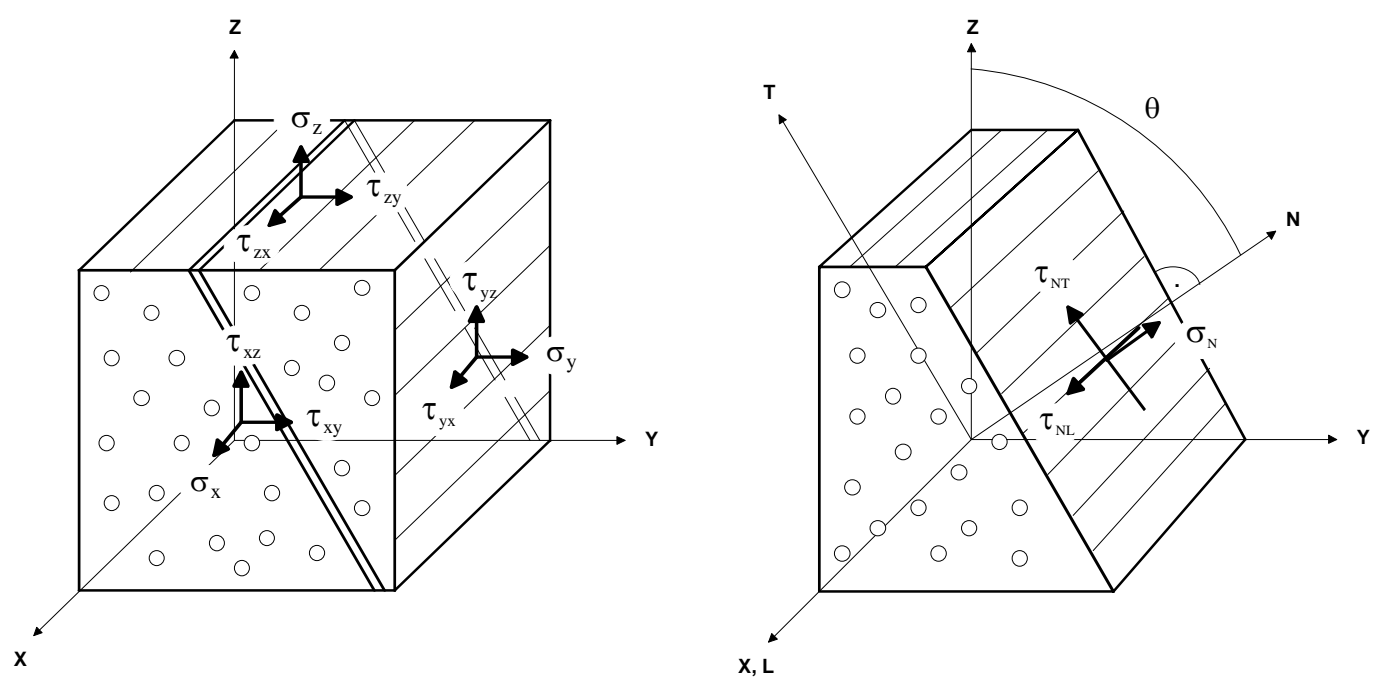

Figure 1.3: Components of the stress tensor and stresses in the fracture plane of an unidirectional composite layer

The above mentioned criteria were developed for unidirectional layers in a threedimensional stress state, but they can also be used for TFP-layers because the uniaxial symmetry is preserved. Only the material strength values are reduced due to 
reasons mentioned in the next section. The failure criteria for the plane stress, which are implemented in TACO, are a simplified case of the described criteria.

\subsection{Material Properties}

Comparing TFP material properties to prepreg material properties, one can assume that TFP exhibits similar stiffness but smaller material strength values. The material strengths are reduced due to the increased fibre waviness. In addition, the carbon rovings are slightly damaged by the needle threads during the manufacturing process. This leads locally to spatially varying material properties. In a first ply failure analysis this is usually taken into account by a global reduction of the basic material strength values.

The reduction factor depends on the kind of material (fibre and resin) and the manufacturing process. The compressive strength, for instance, which had the most significant influence on fracture for the geometries considered, can be between $40 \%$ and $70 \%$ of prepreg compressive strength. Even higher values were recently achieved by Hightex [1]. Still, it is difficult to assume exact material strengths values for the simulation of structures made in TFP technology.

For the optimization of the HTP connection beam (cf. Section 1.5) the following material strengths were taken:

1) In a first approach the best known TFP material strengths values (e.g. the compressive strength is $70 \%$ of prepreg compressive strength) were assumed in order to find the load carrying capacity limits of the HTP connection beam made in TFP technology.

2) After testing of the optimized HTP connection beam the computed maximum loads at first ply failure and maximum test loads were equalized and realized material strength values were estimated.

\subsection{Optimization of the HTP Connection Beam in TFP Technology}

\section{General}

The tool TACO was applied to design a preliminary version of the horizontal tail plane (HTP)-connection beam in TFP technology. The HTP-connection beam is the back connection between the horizontal tail plane and the Section 19 of the fuselage (cf. Figure 1.4). For the A340 version it is currently made of fabrics using composite technology. In the design phase, several geometries and layouts were designed by Airbus. One of the geometries that were built and tested is depicted in Figure 1.5. In the following of this paper this structure will be called conventional HTP connection beam. 
In order to increase the load carrying capacity of the conventional HTP connection beam, the orientations of the rovings and their lay-up were considered for the optimization. The geometry and the total thickness were defined by the testing equipment and the mold available.

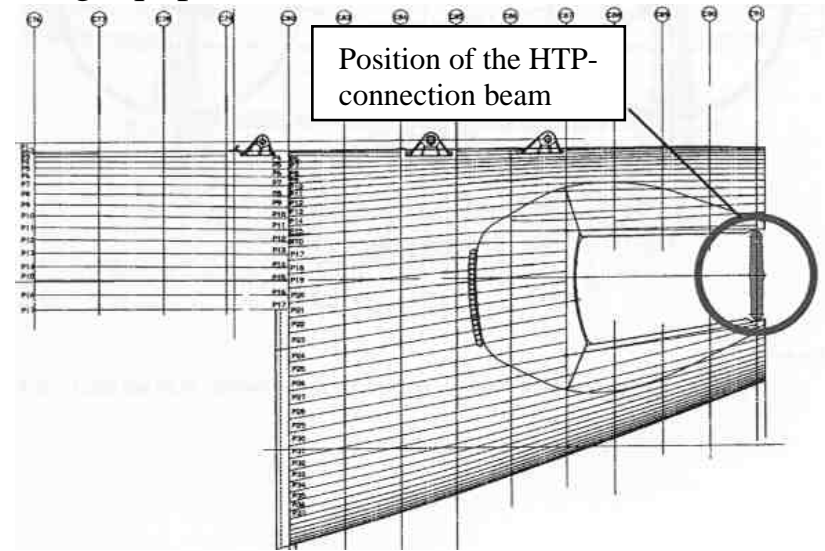

Figure 1.4: Position of the HTP connection beam within Section 19 of the fuselage [2]

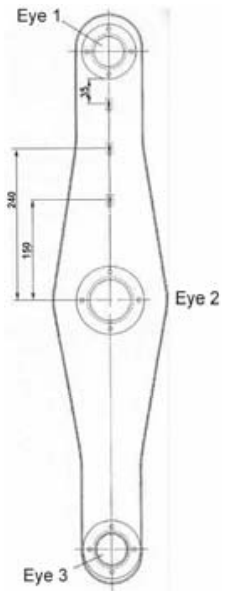

Figure 1.5: HTP connection beam [2]

TACO can be used to optimize the fibre orientations in a certain layer. In order to simplify the optimization for the HTP connection beam, TACO was applied to optimize the $0^{\circ}$-layers only. The $90^{\circ}$-layers were assumed to be orthogonal to the optimized $0^{\circ}$-layers or were omitted. The $\pm 45^{\circ}$-layers were left unchanged. In order to find the optimal ratio of optimized $0^{\circ} / 90^{\circ}$-layers and $\pm 45^{\circ}$-layers, calculations were performed for different realistic ratios. The optimal ratio was selected. In order to find out the necessity of the $90^{\circ}$-layers, calculations were performed for different ratios with and without these layers. The result was that for the geometry considered and a constant number of total layers, the load carrying capacity was without $90^{\circ}$ layers maximal. Due this reason the lay-up of the following optimizations considered only optimized $0^{\circ}$-layers and unchanged $\pm 45^{\circ}$-layers.

\section{Load Cases}

The HTP-connection beam is loaded at the central eye by the tail plane. The loads are transferred through the beam to the outer eyes and into the fuselage section. Due to the geometry of the beam, three independent load cases (tension, combined compression/tension and bending) had to be considered.

Test results for the conventional HTP-connection beam are given in Table 1.1. All loads are normalized by the reference load P.

\section{Modelling}


The HTP connection beam was modelled using 9000 shell-elements (3-node and 4node). The geometry of the structure is depicted by the illustration in Table 1.1. During the experiment, the eyes were loaded using metallic bolts that were kept in place by an adhesive. In the FE model, the bolts, which are significantly stiffer than the HTP connection beam, were modelled as rigid bodies. The adhesive was considered as elastic material. During loading the adhesive generally breaks in the tension area between the metallic bolt and the HTP connection beam. The main load is therefore brought into the structure in the compression area between the bolts and the HTP connection beam. In order to take this in the linear TACO computation into account, the adhesive material properties in the tension area are artificially reduced to $10 \%$ of the compressive values.

\begin{tabular}{|c|c|c|c|}
\hline$\stackrel{0.94 \mathrm{P}}{\longrightarrow}$ & ye 1 & $\downarrow 0.81 \mathrm{P}$ & $\begin{array}{l}\text { Eye } 3 \\
\mathrm{C}^{0.85} \mathrm{P}\end{array}$ \\
\hline & $\begin{array}{c}\text { Load case } 1 \\
\text { Tension }\end{array}$ & $\begin{array}{c}\text { Load case } 2 \\
\text { Tension / Compression }\end{array}$ & $\begin{array}{c}\text { Load case } 3 \\
\text { Bending }\end{array}$ \\
\hline Eye 1 & $0.94 \mathrm{P}$ & $\mathrm{P}$ & Fixed \\
\hline Eye 2 & Fixed & Fixed & $0.81 \mathrm{P}$ \\
\hline Eye 3 & $0.85 \mathrm{P}$ & $0.85 \mathrm{P}$ & Fixed \\
\hline
\end{tabular}

Table 1.1: Test results for the conventional HTP-connection beam

\section{Validation of the Finite Element Model}

In order to test the selected FE model and the loading assumptions, the conventional HTP connection beam was simulated for all 3 load cases given in Table 1.1. Compared was the maximum load at the first ply failure with the maximum test loads. In all 3 load cases the loads at the first play failure were not more than $8 \%$ below the corresponding maximum test loads. This is an acceptable agreement and justifies the assumptions that were made in the FE model.

\section{Optimization for the Combined Load Case Tension and Bending (not recommended)}

The optimization of the HTP connection beam in TFP technology was performed for different load case combination as well as for all single load cases. The optimization for load combinations with the load case 3 (bending) did not lead to an improvement 
of the load carrying capacity. Exemplary for these investigations, only results obtained for the combined load case 1 and 3 (tension and bending) are given here. For the optimization, the roving orientations of all $0^{\circ}$-layers were considered. The $90^{\circ}$-layers were omitted and the $\pm 45^{\circ}$-layers were left unchanged. Figure 1.6 shows the solution for the optimized $0^{\circ}$-layers. It can be seen that the rovings are not symmetric due to the non-symmetric load case bending. In addition, the distance of the rovings near the outer eyes is not constant which leads to varying thickness of the structure as well as varying fibre volume content. Such a non-symmetric distribution of rovings is therefore not acceptable for a reasonable production. In addition, the load carrying capacity of that optimized structure could not be increased in comparison to the conventional HTP connection beam. Based on these results one can conclude that it is not reasonable to apply the optimization procedure to the HTP connection beam for non-symmetric load cases.

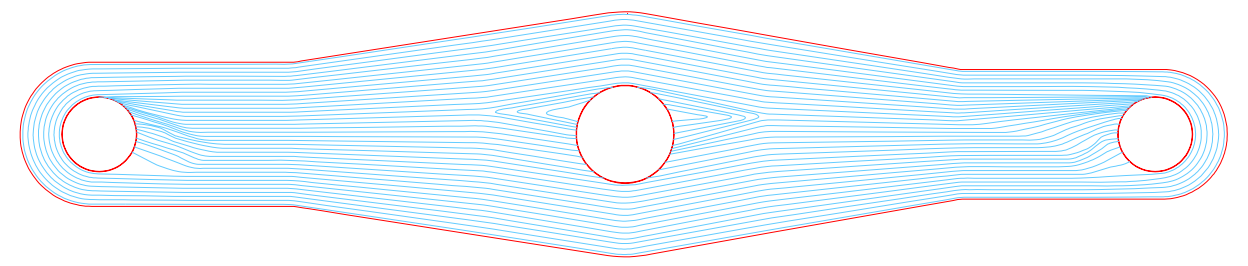

Figure 1.6: Rovings of the HTP connection beam, optimized for the combined load case tension and bending (not recommended)

\section{Optimization for the Load Case Tension}

The best optimization approach was obtained when considering only the single load case 1 (tension). For the optimization, the roving orientations of all $0^{\circ}$-layers were considered. The $90^{\circ}$-layers were omitted and the $\pm 45^{\circ}$-layers were left unchanged. Figure 1.7 shows the solution for the optimized $0^{\circ}$-layers.

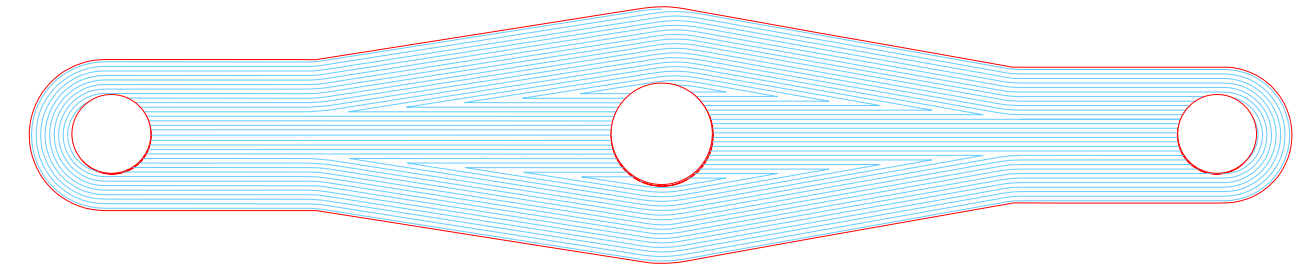

Figure 1.7: Rovings of the HTP connection beam, optimized for the load case 1 (tension)

Figure 1.7 was generated by reading the orientations of the optimized finite elements from the result files. They were then converted to continuous lines. 
Manufacturing restrictions were taken into account. This figure was used during the manufacturing process for placing the TFP rovings.

Table 1.2 shows the expected maximum loads at first play failure, the kind of failure and its layer. These loads are compared to the maximum test loads of the conventional HTP connection beam. The last row gives the expected improvement in percentage. It can bee seen that load case 3 is the most critical one. For that load case the load carrying capacity could be improved by $27.1 \%$. For the other load cases there is a significant higher capacity. However, it must be emphasized that the best known material strength were taken and therefore probably too high load levels are expected. On the other hand, limits of TFP are made visible.

\begin{tabular}{|c|c|c|c|c|c|}
\hline & \multirow{3}{*}{ Load case } & & \multicolumn{2}{|c|}{ Load case 2} & \multirow{3}{*}{$\begin{array}{c}\begin{array}{c}\text { Load } \\
\text { case } 3\end{array} \\
\text { Bending } \\
\text { (Eye 2) }\end{array}$} \\
\hline & & \multicolumn{2}{|c|}{ Load case 1} & & \\
\hline & & $\begin{array}{l}\text { Tension } \\
\text { (Eye 1) }\end{array}$ & $\begin{array}{l}\text { Tension } \\
\text { (Eye 3) }\end{array}$ & $\begin{array}{c}\text { Compression } \\
\text { (Eye 1) }\end{array}$ & \\
\hline \multirow{3}{*}{ 第 } & $\begin{array}{l}\text { Failure mode } \\
\text { Layer }\end{array}$ & $\begin{array}{c}\mathrm{FF} \\
\left( \pm 45^{\circ} \text {-layer }\right)\end{array}$ & $\begin{array}{c}\mathrm{FF} \\
\left( \pm 45^{\circ} \text {-layer }\right) \\
\end{array}$ & $\begin{array}{c}\text { IFF } \\
\left(0^{\circ} \text {-layer }\right)\end{array}$ & $\begin{array}{c}\text { FF } \\
\left(0^{\circ} \text {-layer }\right)\end{array}$ \\
\hline & Optimized HTP & \multicolumn{4}{|c|}{ Maximum load at first ply failure } \\
\hline & $\begin{array}{l}\text { (best known TFP } \\
\text { material strengths) }\end{array}$ & 2.09P & $1.88 \mathrm{P}$ & $2.65 \mathrm{P}$ & $1.03 \mathrm{P}$ \\
\hline \multirow{2}{*}{ 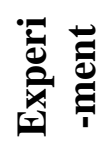 } & \multirow{2}{*}{$\begin{array}{l}\text { Conventional HTP } \\
\text { connection beam } \\
\text { (cf. Table 1.1) }\end{array}$} & \multicolumn{4}{|c|}{ Maximum test load } \\
\hline & & 0.94P & $0.85 \mathrm{P}$ & $\mathrm{P}$ & $0.81 \mathrm{P}$ \\
\hline \multicolumn{2}{|c|}{ Expected improvement in \% } & 122.3 & 121.2 & 165 & 27.1 \\
\hline
\end{tabular}

Table 1.2: Expected maximum loads of the optimized HTP connection beam in comparison to the conventional HTP connection beam 


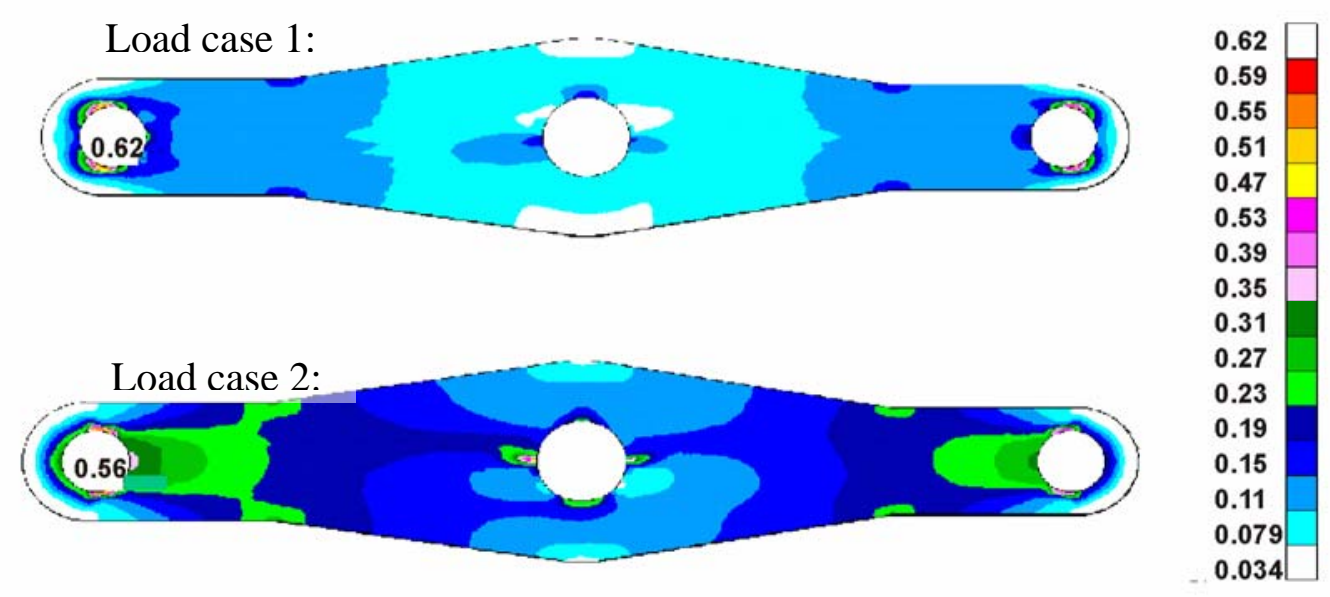

Figure 1.8: Distribution of the material efforts for load cases 1 and 2

For the given loads of Table 1.1 and a fixed geometry, this optimized solution would lead to a reduced thickness of $27 \%$. For this case, Figure 1.8 shows the distribution of material efforts. It can be seen that for load cases 1 (tension) and 2 (combined tension/compression) first failure would occur in the eyes and that in the structure there are still large reserve capacities. For load case 3 (bending) first failure starts at the knee of the outer geometry. This behaviour is plausible.
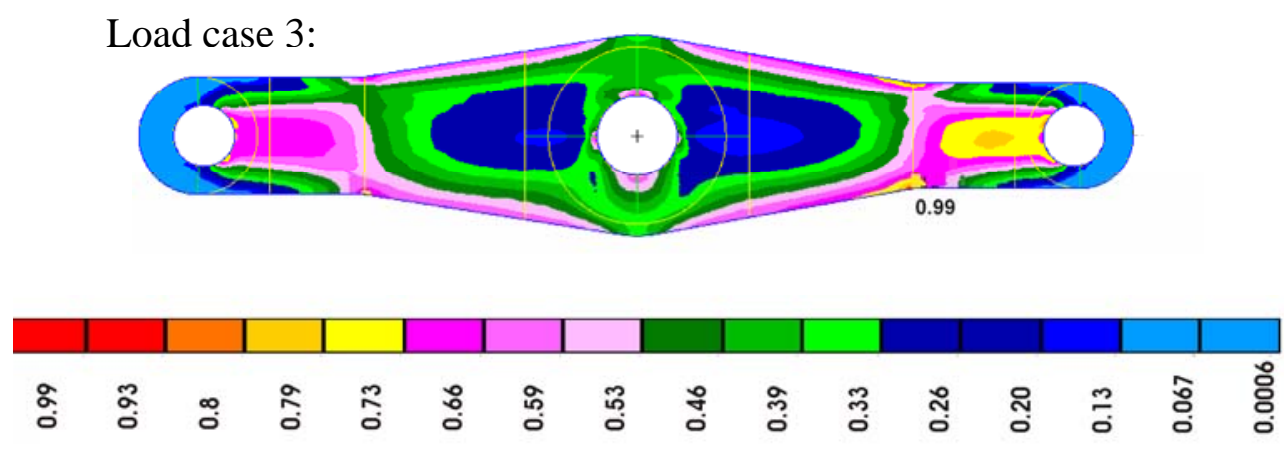

Figure 1.9: Distribution of the material efforts (load case 3)

\section{Test Results}

Airbus Germany (plant Stade) manufactured three nominally equal HTP-connection beams according to the result obtained by TACO and tested each of them for one of the three different load cases [2]. In order to estimate the actual material properties, the maximum test loads and the simulated loads at first ply failure of the TFP optimized HTP connection beam were equalized. The test results were compared to the available test results for the conventional HTP-connection. Table 1.3 summarizes all these results. 


\begin{tabular}{|c|c|c|c|c|c|}
\hline \multirow{3}{*}{\multicolumn{2}{|c|}{ Load case }} & & \multicolumn{2}{|c|}{ Load case 2} & \multirow{3}{*}{$\begin{array}{c}\text { Load } \\
\text { case } 3 \\
\text { Bending } \\
\text { (Eye 2) }\end{array}$} \\
\hline & & \multicolumn{2}{|c|}{ Load case 1} & & \\
\hline & & $\begin{array}{l}\text { Tension } \\
\text { (Eye 1) }\end{array}$ & $\begin{array}{l}\text { Tension } \\
\text { (Eye 3) }\end{array}$ & $\begin{array}{l}\text { Compression } \\
\text { (Eye 1) }\end{array}$ & \\
\hline \multirow{2}{*}{ 呫 } & \multirow{2}{*}{$\begin{array}{l}\text { Optimized HTP connection } \\
\text { beam (realized TFP } \\
\text { material properties) }\end{array}$} & \multicolumn{4}{|c|}{ Maximum load at first ply failure } \\
\hline & & $1.60 \mathrm{P}$ & $1.41 \mathrm{P}$ & $1.78 \mathrm{P}$ & $0.75 \mathrm{P}$ \\
\hline \multirow{3}{*}{ • } & \multirow{2}{*}{$\begin{array}{l}\text { Optimized HTP connection } \\
\text { beam }\end{array}$} & \multicolumn{4}{|c|}{ Maximum test load } \\
\hline & & $1.51 \mathrm{P}$ & $1.36 \mathrm{P}$ & $1.79 \mathrm{P}$ & $0.75 \mathrm{P}$ \\
\hline & $\begin{array}{l}\text { Conventional HTP } \\
\text { connection beam }\end{array}$ & $0.94 \mathrm{P}$ & $0.85 \mathrm{P}$ & $\mathrm{P}$ & $0.81 \mathrm{P}$ \\
\hline \multicolumn{2}{|c|}{ Improvement in \% } & 61 & 60 & 79 & -8 \\
\hline
\end{tabular}

Table 1.3: Comparison of maximum loads of the HTP connection beam

The last row in Table 1.3 shows how the load carrying capacity of the HTP connection beam is improved by the TFP optimization. One can see that for load case 3 the structural behaviour of the HTP connection beam is $8 \%$ worse. One reason for the early onset of failure within that load case can be interlaminar stresses due to the accumulation of needle threads at the boundaries of the layers between the sub-preforms. For load case 1 and 2 there is, however, a significant improvement of $60 \%$ and $79 \%$, respectively.

Based on these results one can conclude that the TFP technology is not suitable for structures which are subjected to too many different load cases. However, if a structure is loaded by only 1 or 2 clearly defined load case, TFP promises large reserve capacities which can lead to significant weight reduction.

\subsection{Concluding Remarks}

The TFP optimization tool TACO is capable of changing the fibre orientations within a selected layer of a composite Finite Element model. For a given load case, the fibres are aligned as closely as possible to the direction of the principal stresses. In this way, the shear stresses in the structure are minimized and thus its loadcarrying capacity is increased.

TACO was used to optimize a preliminary version of the HTP connection beam a part of the Airbus A340-500/600 fuselage structure - in TFP technology. The HTP connection beam is currently manufactured in conventional composite technology made of fabrics and is subjected to three independent load cases; that is, two symmetric (tension and compression) load cases and one non-symmetric load case (bending). 
In a first approach the combined load case tension and bending was considered. Due to the non-symmetric load case bending the optimized fibre orientations are also non-symmetric. The load-carrying capacity could not be increased. In a second approach the structure was optimized for the load case tension only. This concept led to a reasonable solution for which manufacturability could be ensured.

After TACO had suggested an optimal fibre orientation, the HTP connection beam was manufactured three times. Each test structure was tested according to one of the three load cases. The test results were compared to test results for a conventional HTP connection beam made of fabrics that had been tested earlier. For the load case bending the load carrying capacity was $8 \%$ worse, however, for the other load cases there was a significant improvement of about $60 \%$ for tension and $79 \%$ for compression.

Based on these results it can be concluded that the optimization criterion that was chosen is not suitable for structures which are subjected to too many different load cases. However, TFP promises reserve capacities and significant weight reduction for structures which are subjected to a smaller number of load cases. 


\section{2 iBuck - a Rapid Design Tool for Stiffened Panels}

\subsection{Introduction}

In a conventional aluminium aircraft, the aircraft fuselage (cf. Figure 2.1) is typically comprised of a shell (skin) and stiffeners in both longitudinal (stringers) and circumferential direction (frames). In order to save weight, the skin is usually very thin. If such a fuselage is loaded in-plane, the skin can deflect laterally. This effect is called buckling and must be accounted for when designing the aircraft. While some buckling modes are not critical, others may result in collapse and must therefore be avoided in aircraft operation.

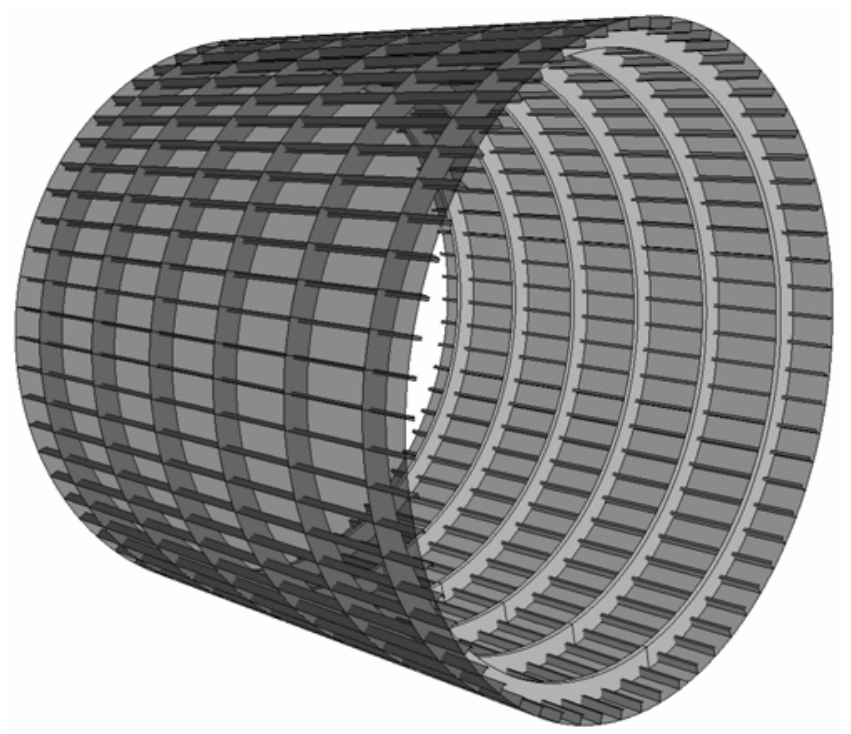

Figure 2.1: An aircraft fuselage section.

When buckling occurs, the applied load is partially re-distributed across the cross-section of the structure where the stiffeners will attract load from the buckled skin. In local buckling modes (pure skin buckling within a bay) the load may be increased further without loss of overall stability. In global buckling modes (buckling across several bays), the stability of the structure is severely reduced and collapse can occur.

It is thus necessary to identify both local and global buckling modes. More specifically, it is necessary to investigate the effect of local buckling on the overall stability of the structure while the load is increased. Therefore the post-buckling behaviour of the structure, that is, the behaviour of the structure at loads beyond the buckling load of the skin must be described. 
Efforts have been made ever since aluminium aircrafts are built and a wide range of analytical hand-book-type formulas are available. However, these formulas often are only estimates and merely predict the onset of buckling while post-buckling is not described. Also, these methods are limited to relatively simple geometries.

On the other end, commercially non-linear FE-tools such as ABAQUS are available. However, modelling and computation may be very costly. A detailed discussion of the capabilities of non-linear FE analysis concerning aerospace structures may be found in [31] and [32].

With these two options in mind, it is desirable to provide a compromise between accuracy and computational cost. Such a fast tool, the semi-analytical tool "iBuck" was developed and is presented subsequently.

In [22] and [23], unstiffened plates undergoing large deflection are considered. The concept of choosing shape functions for the skin deflection is introduced. Expressions for the bending and membrane energy are presented in [20]. [21] provides a comprehensive background on shell theory.

In [25] a semi-analytical model for unstiffened plates is presented. The concept of choosing shape functions and determining the total energy is adopted. Loadinteraction curves are given. In [24], shape functions for the stiffener deflection are presented and discussed.

Byklum's publications [26]-[28] are the basis for the present paper. Byklum considers longitudinally (stringer-)stiffened heavy plates and chooses shape functions for the skin and the stringers. The equations are solved by minimizing the system's energy using an arc-length method ([29],[30]). The frames are assumed to be rigid and are considered through boundary conditions.

In this paper, this concept is extended to thin cylindrical shells that are stiffened in both longitudinal and circumferential direction. Hence, a curved structure is considered. For both the stringers and the frames appropriate shape functions are chosen in order to predict both stringer and frame failure. For frames with high blades, lateral instabilities may occur and must therefore be investigated.

\subsection{Representative Panel}

In this paper, a semi-analytical tool that is capable of predicting the local buckling response of a stiffened panel is presented.

In this context, semi-analytical means that the problem formulation is entirely based on the foundations of analytical continuum mechanics. However, numerical methods are used to solve the equations at each load step. 
By local buckling it is meant that the skin within a bay may deflect laterally and may induce rotation of the stiffeners. However, the stiffeners themselves are not allowed to deflect in out-of-plane direction, that is, points A and B in Figure 2.2 may not move in z-direction.

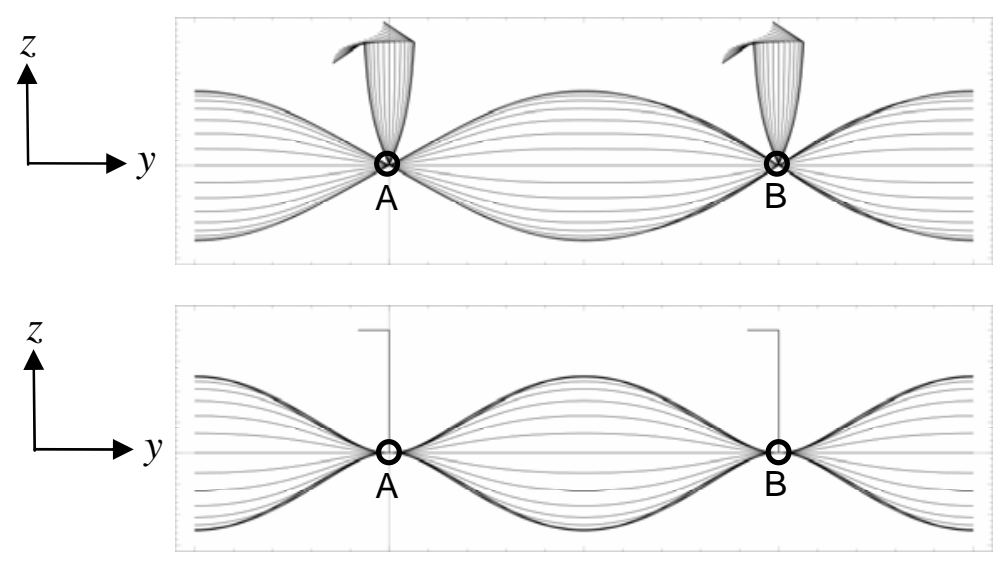

Figure 2.2: Local buckling shapes.

Figure 2.2 depicts how weak stiffeners deflect laterally (top), thus suggesting a sinus-type buckling shape. In other words, from the skin's perspective, weak stiffeners act as simply-supported boundary conditions. At the bottom of Figure 2.2, strong stiffeners force the skin to assume zero slope at the stiffeners' feet. Thus, strong stiffeners create clamped boundary conditions for the skin. In Figure 2.2, the stringer deflections are displayed. Deflection functions for the frames were chosen accordingly.

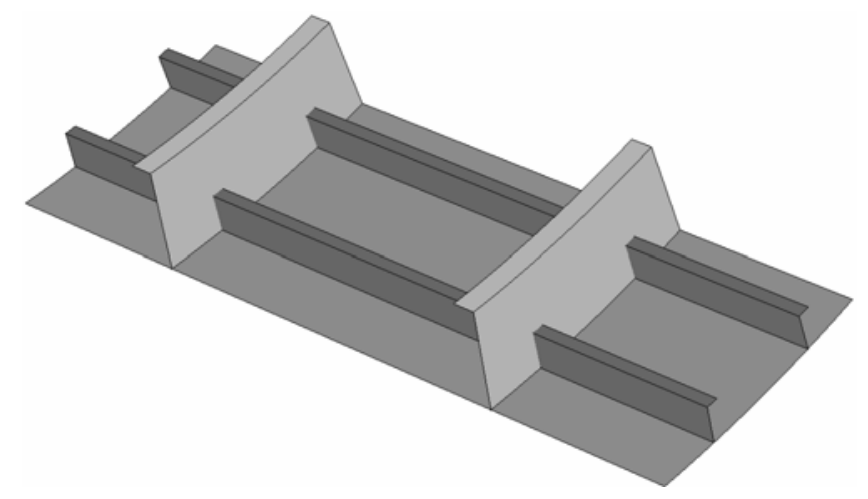

Figure 2.3: A representative stiffened panel.

With these mode shapes in mind it is then assumed that a large structure such as the fuselage in Figure 2.1 can be represented by a panel such as the one depicted in Figure 2.3. However, this assumption is only valid if local buckling modes are considered, that is, buckling is only permitted within a bay. 
In the following section it will be explained how the structure is modelled. In Section 2.3 the Donnell differential equations for a pre-deformed (imperfect) cylindrical shell and a solution strategy is presented. In Section 2.4 it is outlined how a stiffened structure is modelled.

\subsection{Non-Linear Shell Theory}

\section{The Donnell Equations}

The Donnell shell equations are valid for a thin, weakly curved shell undergoing large out-of-plane deflections. They can be given as

$$
\begin{aligned}
& K \Delta \Delta w=h\left[\frac{F_{, x x}}{R}+F_{, x x}\left(w+w_{0}\right)_{, y y}+2 F_{, x y}\left(w+w_{0}\right)_{, y y}+F_{, y y}\left(w+w_{0}\right)_{, x x}\right] \\
& \Delta \Delta F=E\left[w_{, x y}^{2}-w_{, x x} w_{, y y}+2 w_{, x y} w_{0, x y}-w_{, x x} w_{0, y y}-w_{, y y} w_{0, x x}-\frac{\left(w+w_{0}\right)_{, x x}}{R}\right]
\end{aligned}
$$

Here, $w(x, y)$ and $w_{0}(x, y)$ are the lateral shell deflection and the initial shell imperfection, respectively. $K$ is the bending stiffness while $F(x, y)$ is a potential function that is related to the in-plane stresses of the neutral plane. We have

$$
\begin{gathered}
\sigma_{x x}=F_{, y y} \\
\sigma_{y y}=F_{, x x} \\
\tau_{x y}=-F_{, x y}
\end{gathered}
$$

Plane-stress state is assumed

$$
\begin{aligned}
& \sigma_{x x}=\frac{E}{1-v^{2}}\left(\varepsilon_{x}+v \varepsilon_{y}\right) \\
& \sigma_{y y}=\frac{E}{1-v^{2}}\left(\varepsilon_{y}+v \varepsilon_{x}\right) \\
& \tau_{x y}=\frac{E}{2(1+v)} \gamma_{x y}
\end{aligned}
$$

while the strains can be expressed by 


$$
\begin{aligned}
\varepsilon_{x} & =u_{, x}-z w_{, x x}+\frac{1}{2} w_{, x}^{2}+w_{, x} w_{0, x} \\
\varepsilon_{y} & =v_{, y}-\frac{w}{R}-z w_{, y y}+\frac{1}{2} w_{, y}^{2}+w_{, y} w_{0, y} \\
\gamma_{x y} & =u_{, y}+v_{, x}-2 z w_{, x y}+w_{, x} w_{, y}+w_{, x} w_{0, y}+w_{0, x} w_{, y}
\end{aligned}
$$

It should be noted that the Donnell shell equations describe the neutral plane of the shell $(z=0)$ while the strains in Equation (2.5) include a contribution from bending.

\section{The Solution of the Donnell Equations}

Since there is no analytical solution to the Donnell equations, some approximation must be found. First, Equation (2.1) is considered. A set of displacement or shape functions of the form

$$
\begin{aligned}
& w(x, y)=\sum_{m=1}^{M} \sum_{n=1}^{N} A_{m n} \cdot g_{m}(x) \cdot g_{n}(y) \\
& w_{0}(x, y)=\sum_{m=1}^{M} \sum_{n=1}^{N} B_{m n} \cdot g_{m}(x) \cdot g_{n}(y)
\end{aligned}
$$

is chosen. $w(x, y)$ and $w_{0}(x, y)$ are defined on the bay between two stringers and two frames and must satisfy the boundary conditions at the shell edges, that is, either simply-supported or clamped boundary conditions. In general, $g_{m}(x)$ and $g_{n}(y)$ may be any functions satisfying the boundary conditions. However, trigonometric functions are often preferred.

It must be noted that the shape functions from Equation (2.6) are defined on the entire bay. Thus, from a numerical point of view, global shape functions (in the sense that they are valid on the entire structure) are chosen. It is therefore consequent to use the Rayleigh-Ritz method to solve the resulting equations. In contrast, in the finite element method, (numerically) local shape functions, which are only defined within an element, are used.

By substituting Equation (2.6) in Equation (2.1), the potential function $F(x, y)$ can be found. It is of the form

$$
F(x, y)=-T_{x} \frac{y^{2}}{2}-T_{y} \frac{x^{2}}{2}+T_{x y} x y+\sum_{m} \sum_{n} f_{m n}\left(A_{m n}, B_{m n}\right) \cdot h_{m}(x) \cdot h_{n}(y)
$$

where $h_{m}(x)$ and $h_{n}(y)$ are shape functions and $f_{m n}\left(A_{m n}, B_{m n}\right)$ is some operator that depends on the unknown coefficients $A_{m n}$ and $B_{m n} . T_{x}, T_{y}$ and $T_{x y}$ are the 
external loads. The second Donnell Equation (2.2) is not solved directly. Instead, the total energy of the system is found and the principle of minimum potential energy is used to find a solution. This is equivalent to solving Equation (2.2) directly but much more convenient and numerically efficient. We have

$$
\delta \Pi=\delta(U-T)=0
$$

where $U$ and $T$ are the internal energy of the structure and the potential of the external loads, respectively. Since we have already chosen appropriate lateral deflection functions, we can re-formulate the variational problem by using the Rayleigh-Ritz method and obtain

$$
\frac{\partial(U-T)}{\partial A_{m n}}=0
$$

Equation (2.9) is of third order in unknown coefficients $A_{m n}$ and thus an appropriate numerical method must be used in order to solve it. The imperfection coefficients $B_{m n}$ may generally be chosen arbitrarily and are therefore not unknown.

In the following paragraphs, the internal Energy $U$ and the potential of external loads $T$ will be derived for an unstiffened, cylindrically curved shell. A similar derivation for an unstiffened plate and more details can be found in [26] and [28].

\section{The Internal Energy}

For a 3-dimensional continuum of volume $V$, we have

$$
U=\frac{1}{2} \sum_{i, j} \int_{V} \sigma_{i j} \varepsilon_{i j} d V \quad \text { for } \quad i, j=x, y, z
$$

Assuming pure in-plane stress state, and using technical notation, Equation (2.10) can be given as

$$
U=\frac{1}{2} \int_{V}\left(\sigma_{x x} \varepsilon_{x}+\sigma_{y y} \varepsilon_{y}+\tau_{x y} \gamma_{x y}\right) \cdot d V
$$

where both the stresses and the strains may be divided into a bending part and contribution from membrane stretching. Substituting the stresses from Equation (2.3) and the strains from Equation (2.5), and using Hooke’s law (2.4), we obtain 


$$
\begin{aligned}
& U=U_{m}+U_{b} \\
& U_{m}=\frac{h}{2 E} \int_{V}\left[\left(F_{, x x}+F_{, y y}\right)^{2}-2(1+v)\left(F_{, x x} F_{, y y}-\left(F_{, x y}\right)^{2}\right)\right] \cdot d V \\
& U_{b}=\frac{K}{2} \int_{V}\left[\left(w_{, x x}+w_{, y y}\right)^{2}-2(1-v)\left(w_{, x x} w_{, y y}-\left(w_{, x y}\right)^{2}\right)\right] \cdot d V
\end{aligned}
$$

\section{The Potential of External Loads}

For a 3-dimensional solid of surface $S$, we have

$$
T=\sum_{i} \oint_{S} t_{i} u_{i} d S \quad \text { for } \quad i=x, y, z
$$

where $t_{i}=\bar{\sigma}_{i j} n_{j}$ and $\bar{\sigma}_{i j}$ are prescribed external loads. Re-writing Equation (2.13) using Gauss integration rule, we obtain

$$
T=-h \int_{A}\left(T_{x} u_{, x}+T_{y} v_{, y}\right) \cdot d A-h \int_{A} T_{x y}\left(u_{, y}+v_{, x}\right) \cdot d A+\int_{A} p_{l} w \cdot d A
$$

where $T_{x}, T_{y}, T_{x y}$ and $p_{l}$ are the prescribed normal loads in $\mathrm{x}$ - and $\mathrm{y}$-direction, the prescribed in-plane shear load and the prescribed lateral pressure, respectively. Using Equation (2.5) with Equation (2.14) and considering only non-constant terms, we obtain

$$
\begin{aligned}
& T=T_{c}+T_{t}+T_{p} \\
& T_{c}=T_{x} h \int_{A}\left(\varepsilon_{x}-\frac{1}{2}\left(w_{, x}\right)^{2}-w_{, x} w_{0, x}\right) d A+T_{y} h \int_{A}\left(\varepsilon_{y}-\frac{1}{2}\left(w_{, y}\right)^{2}-w_{, y} w_{0, y}+\frac{w+w_{0}}{R}\right) d A \\
& T_{t}=T_{x y} h \int_{A}\left(w_{, x} w_{, y}+w_{, x} w_{0, y}+w_{0, x} w_{, y}\right) d A \\
& T_{p}=p_{l} \int_{A} w d A
\end{aligned}
$$

\section{The Riks Method}

A load parameter $\lambda$ is introduced. It is increased from 0 to 1 during the calculation. When starting with an unloaded structure, we have

$$
T_{i}(\lambda)=\lambda \cdot T_{i}^{(s)}
$$

where $T_{i}^{(s)}$ is the load at the end of the step. Since the Riks method is a curvetracing algorithm the load parameter enters the equations as an unknown. 
It is assumed that both the unknown coefficients $A_{m n}$ and the load parameter $\lambda$ depend on a pseudo-time $\eta$ and must be calculated for each load step. We define

$$
\begin{aligned}
& \dot{A}_{m n}=\frac{\partial A_{m n}}{\partial \eta} \\
& \dot{\lambda}=\frac{\partial \lambda}{\partial \eta}
\end{aligned}
$$

Also, it is assumed that $A_{m n}$ and $\lambda$ may be expanded in a Taylor series

$$
\begin{aligned}
& A_{m n}^{(i)}=A_{m n}^{(i-1)}+\eta \cdot \dot{A}_{m n}^{(i-1)} \\
& \lambda^{(i)}=\lambda^{(i-1)}+\eta \cdot \dot{\lambda}^{(i-1)}
\end{aligned}
$$

that is aborted after the linear term. Geometrically, this means that the cubic equations (2.9) are approximated linearly. Differentiating Equation (2.9) with respect to $\eta$ we have

$$
\frac{\partial}{\partial \eta}\left(\frac{\partial \Pi}{\partial A_{m n}}\right)=\sum_{f, g} \frac{\partial^{2} \Pi}{\partial A_{m n} \partial A_{f g}} \frac{\partial A_{f g}}{\partial \eta}+\frac{\partial^{2} \Pi}{\partial A_{m n} \partial \lambda} \frac{\partial \lambda}{\partial \eta}=0
$$

Defining

$$
\begin{aligned}
& K_{m n f g}=K_{f g m n}=\frac{\partial^{2} \Pi}{\partial A_{m n} \partial A_{f g}} \\
& G_{f g}=\frac{\partial^{2} \Pi}{\partial A_{m n} \partial \lambda}
\end{aligned}
$$

and solving Equation (2.19) at load step (i) for $\dot{A}_{f g}^{(i)}$, we have

$$
\dot{A}_{f g}^{(i)}=-\dot{\lambda}^{(i)} D_{f g}^{(i)}
$$

where

$$
D_{f g}^{(i)}=\sum_{m, n}\left[K_{m n f g}^{(i)}\right]^{-1} G_{m n}^{(i)}
$$

has been introduced. Thus we have $(M \times N)$ equations for $(M \times N+1)$ unknowns. It can be shown that the additional equation can be given as 


$$
\sum_{f, g}\left[\dot{A}_{f g}^{(i)}\right]^{2}+h^{2}\left[\dot{\lambda}^{(i)}\right]^{2}=h^{2}
$$

from which $\dot{\lambda}^{(i)}$ can be found to be

$$
\dot{\lambda}^{(i)}=\operatorname{sign}(\kappa) \cdot \frac{h}{\sqrt{\sum_{f, g}\left[D_{f g}^{(i)}\right]^{2}+h^{2}}}
$$

The sign of $\dot{\lambda}^{(i)}$ depends on the state of the structure at the previous load step $(i-1)$, that is, on a parameter $\kappa$ that can be given as

$$
\kappa=\dot{\lambda}^{(i-1)}-\frac{1}{h^{2}} \sum_{f, g} \dot{A}_{f g}^{(i-1)} D_{f g}^{(i)}
$$

Once $\dot{A}_{f g}^{(i)}$ and $\dot{\lambda}^{(i)}$ are known, $A_{f g}^{(i)}$ and $\lambda^{(i)}$ can be calculated using Equation (2.18). An alternative derivation and more details can be found in [29] and [30].

\subsection{Local Buckling of Stiffened Panels}

\section{Theoretical Background}

Consider the panel in Figure 2.3. As mentioned earlier, it is assumed that the panel is representative for a fuselage structure like the one depicted in Figure 2.1. Note the skin doublers beneath both the stringers and the frames. Please also note that the frames are much stronger than the stringers. It is assumed that there is a perfect connection between the stiffeners (stringers, frames, doublers) and the underlying skin.

The skin is modelled as a Donnell type thin, weakly curved shell. For both the stringer and the frame webs additional degrees of freedom in terms of deflection functions are introduced. The skin doublers and both the stringer and the frame flanges are modelled as bending beams that additionally may carry out torsion.

It must be noted that modelling parts of the structure as beams typically leads to overestimated stiffness. However, depending on the position of the neutral axis (and consequently, the value of the bending stiffness), both too stiff and too soft results have been computed. Improved parameterization still remains subject to future work. 


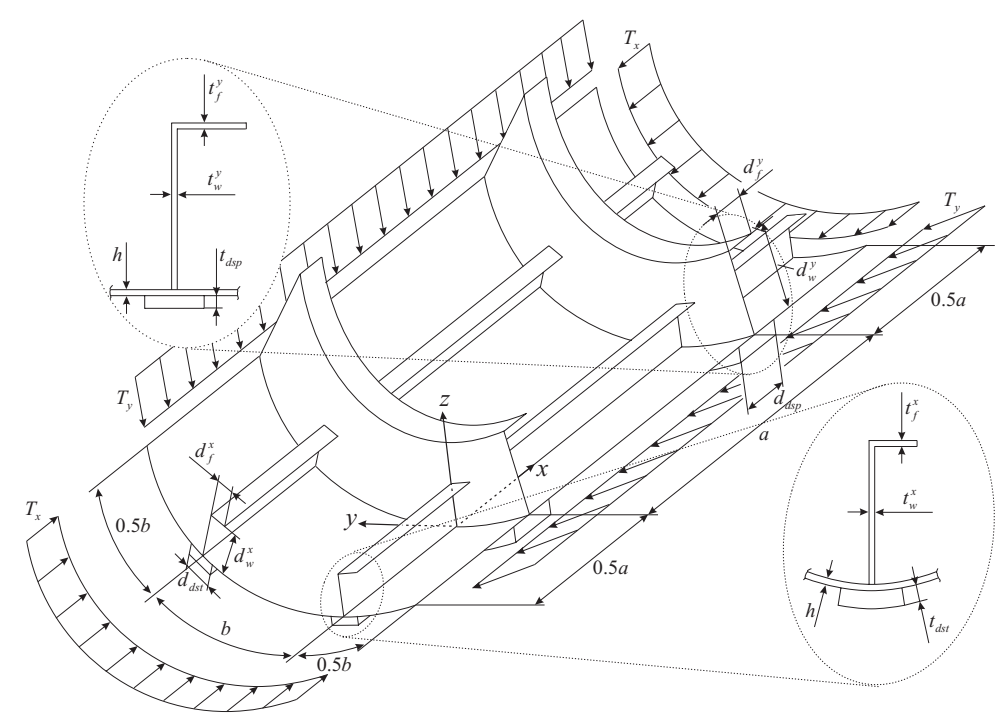

Figure 2.3: A typical stiffened structure.

The structure may be loaded axially (in x-direction), laterally (in y-direction), by in-plane shear stresses or by internal pressure (in z-direction). Any combination of loading may be chosen where the loads are assumed to be constant along the structure's edges. The loads are increased incrementally at each load step as described earlier.

As it is assumed that both the stringers and the frames are rigidly connected to the skin, continuity in terms of a right angle between stiffeners and skin must be satisfied at all times.

Also, longitudinal and transverse continuity must be ensured at all times, that is, the axial and transverse stretching of skin, stiffeners and doublers must be equal.

Finally, the force equilibrium must be satisfied in both axial and transverse direction. The force equilibrium is ensured by requiring the integrated reaction force of skin and stiffeners to be equal to the applied external loads acting on the skin only. This way the load is distributed over the whole cross-section of the stiffened panel.

\section{Implementation}

iBuck was implemented in the $\mathrm{C}$ programming language using Visual $\mathrm{C}++$. Standard clapack routines from the lapack (linear algebra package) package were used to carry out the eigenvalue analysis and for solving the equations at each load step.

First, an eigenvalue analysis is carried out and some combination of the eigenshapes is chosen as imperfection. Then the equations are solved by minimizing 
the elastic potential at each load step according to Equation (2.9). The equations are numerically solved using an arc-length method, the curve-tracing Riks-algorithm.

A powerful visualization routine was also written. At each load step, ASCII files are generated. These files may be opened with the FE pre- and post-processor GID and the results can be visualized.

\section{Results}

In this section, results for three different geometries are presented. The geometric quantities can be taken from Table 2.1. For all computations, aluminium panels with a Young's Modulus $Y=64935 \mathrm{MPa}$, a Poisson's Ratio $v=0.34$ and a yield stress $S_{f}=435 \mathrm{MPa}$ were used. They were loaded axially by a compressive stress $T_{x}=1000 \mathrm{MPa}$. Linear elastic material behaviour was assumed. All load-shortening curves are scaled by the yield stress.

\begin{tabular}{|c|c|c|c|}
\hline & Panel 1 & Panel 2 & Panel 3 \\
\hline$a$ & $400 \mathrm{~mm}$ & $600 \mathrm{~mm}$ & $800 \mathrm{~mm}$ \\
\hline$b$ & \multicolumn{3}{|c|}{$200 \mathrm{~mm}$} \\
\hline$h$ & \multicolumn{3}{|c|}{$2.7 \mathrm{~mm}$} \\
\hline$R$ & \multicolumn{3}{|c|}{$2000 \mathrm{~mm}$} \\
\hline$d_{w}^{x}$ & \multicolumn{3}{|c|}{$60 \mathrm{~mm}$} \\
\hline$d_{f}^{x}$ & \multicolumn{3}{|c|}{$20 \mathrm{~mm}$} \\
\hline$t_{w}^{X}=t_{f}^{X}$ & \multicolumn{3}{|c|}{$3.5 \mathrm{~mm}$} \\
\hline$d_{w}^{y}$ & \multicolumn{3}{|c|}{$160 \mathrm{~mm}$} \\
\hline$d_{f}^{y}$ & \multicolumn{3}{|c|}{$35 \mathrm{~mm}$} \\
\hline$t_{w}^{y}=t_{f}^{y}$ & \multicolumn{3}{|c|}{$2.5 \mathrm{~mm}$} \\
\hline$d_{d s t}=d_{d s p}$ & \multicolumn{3}{|c|}{$40 \mathrm{~mm}$} \\
\hline$t_{d s t}=t_{d s p}$ & \multicolumn{3}{|c|}{$2.3 \mathrm{~mm}$} \\
\hline
\end{tabular}

Table 2.1: Geometric quantities.

The FE analysis was carried out with ABAQUS 6.3.1. The structure was modelled using S4 shell elements with $20 \mathrm{~mm}$ edge length. For all computations (ABAQUS and iBuck), the lowest eigenshape was chosen as imperfection. In ABAQUS, the equations were solved using the damped Newton method (*static,stabilize) with a damping parameter of 1.e-5. 


\section{Results for Panel 1}

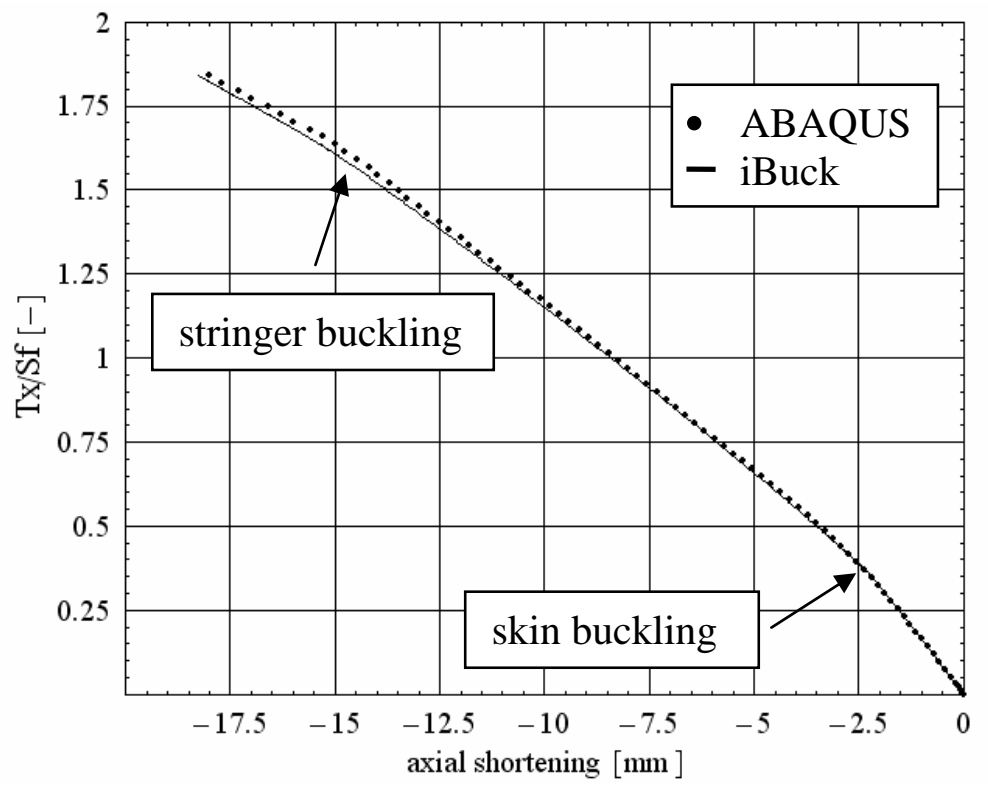

Figure 2.4: Load-deflection curve for Panel 1.

In Figure 2.4 it can be seen that the ABAQUS results (dotted) and the semianalytical iBuck results (solid line) correspond very well. However, iBuck only needed around 30 seconds to compute the complete load-displacement curve while it took ABAQUS (6080 elements) around 40 minutes, that is, iBuck finished 80 times faster.

The corresponding deformed shape depicted in Figure 2.5 was generated by iBuck at maximum load. As mentioned earlier, the FE pre- and post-processor GID is used to visualize the results. This is why the continuous iBuck result is plotted like a discrete FE-solution.

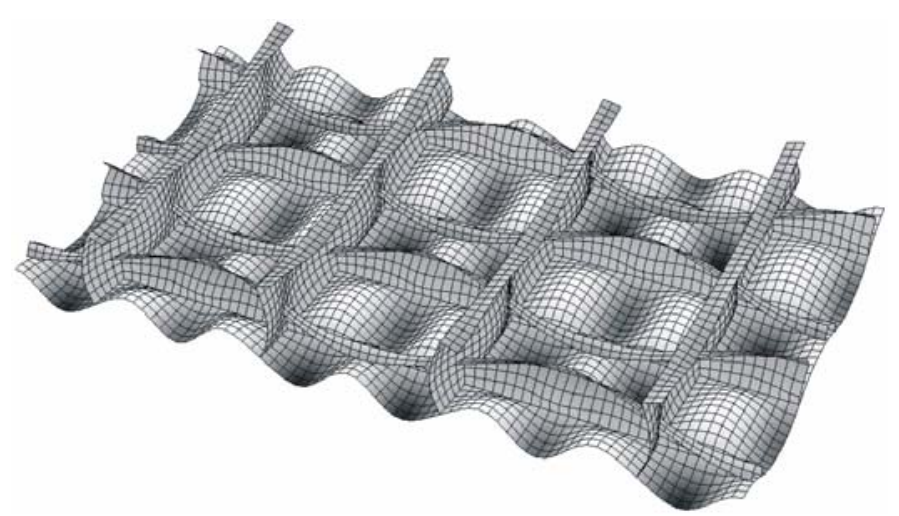

Figure 2.5: Deformed shape for Panel 1. 
It can be seen that the stringers deflect laterally in a different mode than the skin. While the stringers show a 1-wave-pattern the skin exhibits a 3-wave pattern. Stringer buckling occurs at an axial load well above the yield stress.

When stringer buckling occurs, the stiffness of the structure is reduced which results in a change in slope in the load-displacement curve (Figure 2.5). Thus stringer buckling must be avoided in airplane operation. However, since the stiffeners are relatively heavy, it can be seen that the stiffness reduction is not very dramatic. For softer stiffeners, a sharper drop in stiffness may be expected.

\section{Results for Panel 2}

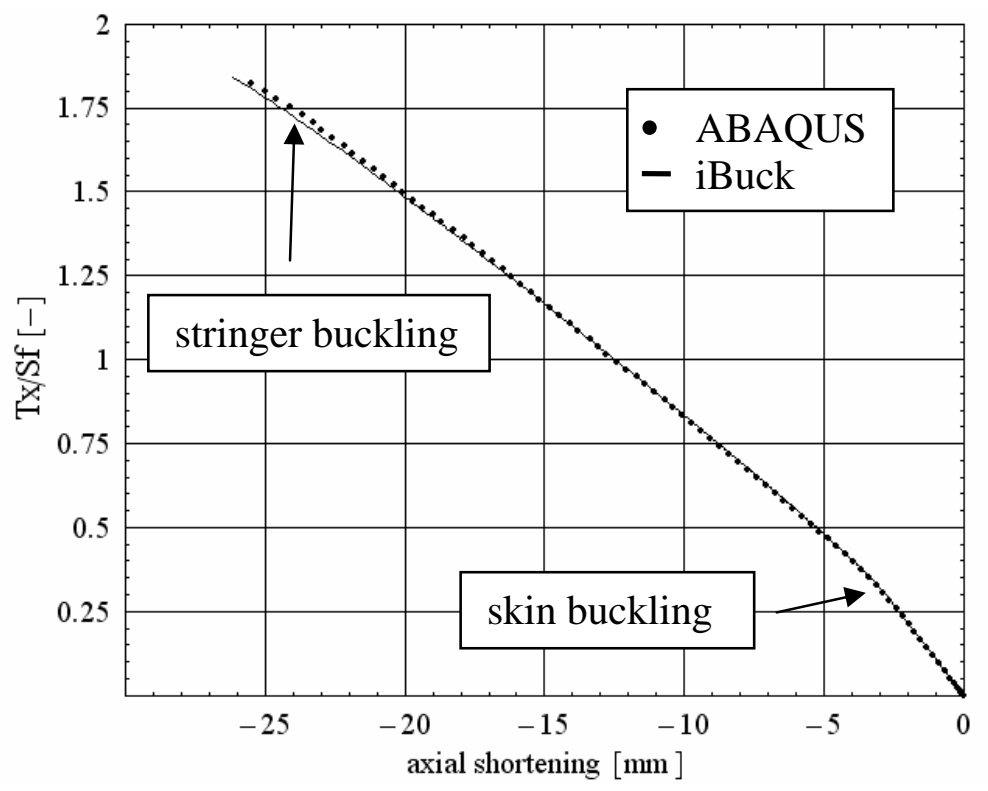

Figure 2.6: Load-deflection curve for Panel 2.

In Figure 2.6, the correspondence between ABAQUS and iBuck is very good. For Panel 2, the computational advantage is even higher when iBuck is used: iBuck finished 100 times faster than ABAQUS (8320 elements). This is due to the fact that the same iBuck-model as for Panel 1 could be used while the FE model for Panel 2 required more elements than the FE model for panel 1.

It can be also seen from Figure 2.6 that stringer buckling occurs at a higher load level than for Panel 1. In Figure 2.7, stringer buckling occurs in a 2-wave pattern while skin buckling occurs in a 4-wave pattern. 


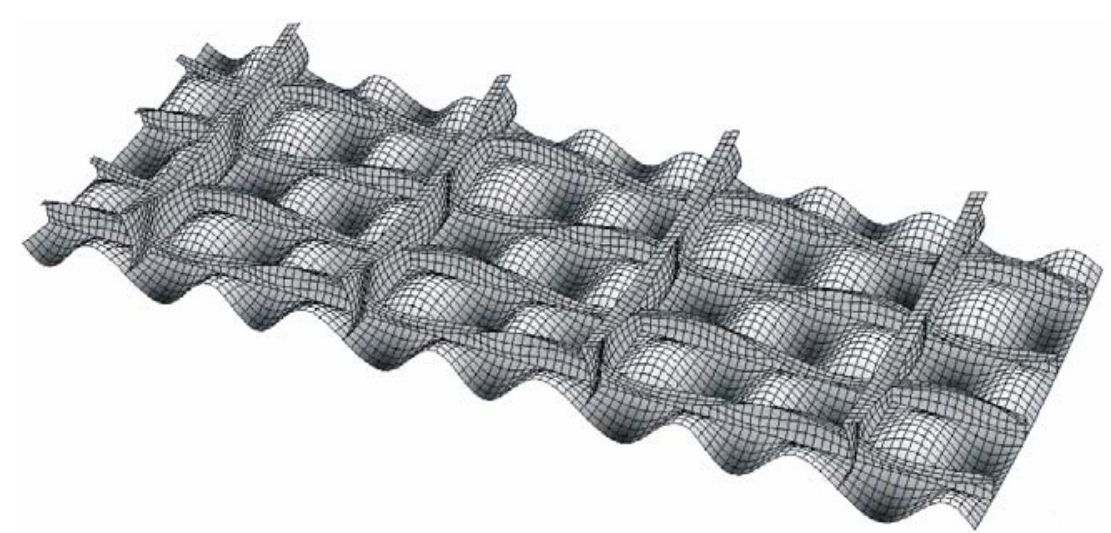

Figure 2.7: Deformed shape for Panel 2.

\section{Results for Panel 3}

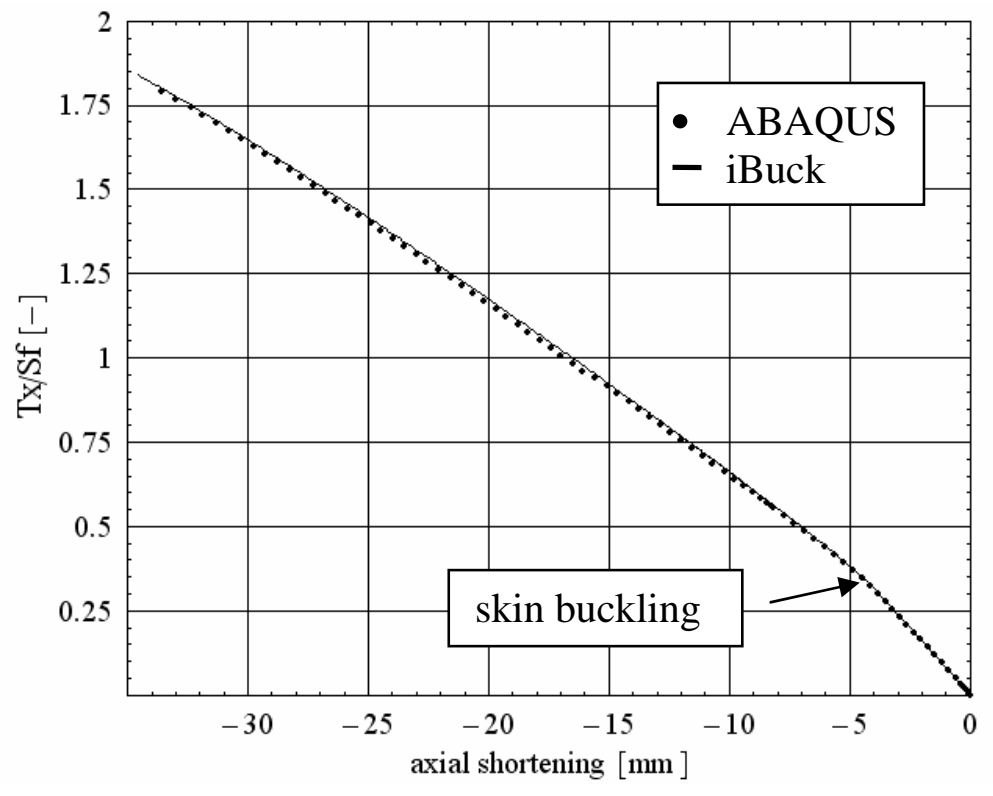

Figure 2.8: Load-deflection curve for Panel 3.

In Figure 2.8 it can be seen that also for Panel 3 the correspondence between ABAQUS (10560 elements) and iBuck is very good. Computational efficiency is 120 times higher when iBuck is used.

The onset of stringer buckling cannot be identified from the load-shortening curve. However, it can be seen that stringer buckling exhibits a 3-wave-pattern while skin buckling is at 5 waves. 


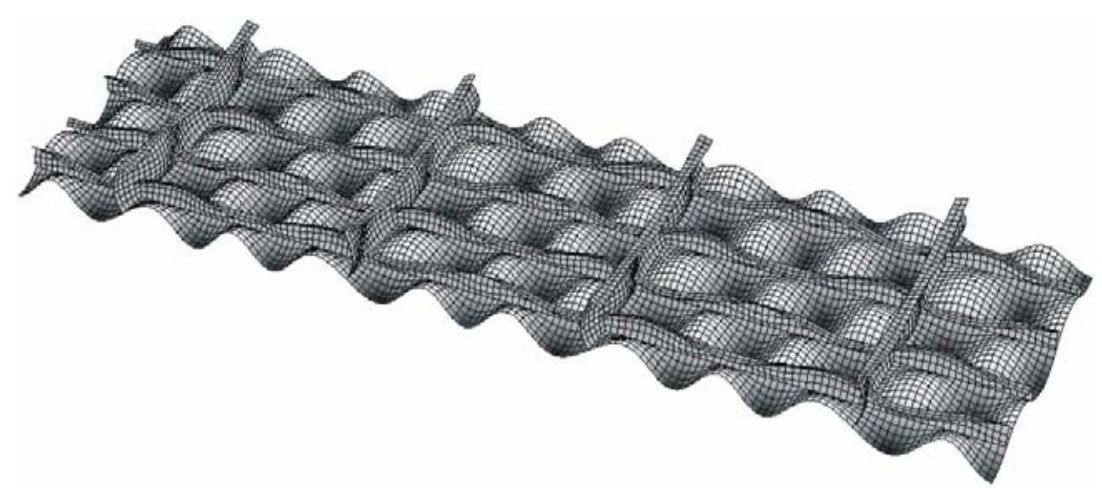

Figure 2.9: Deformed shape for Panel 3.

Comparing the results for Panel $1-3$ it can be seen that Panel 2 is a good compromise between Panel 1 and Panel 3. Panel 1 is of high overall stiffness but is sensitive to stringer buckling. On the other end, Panel 3 is comparatively soft but exhibits only very weak stringer buckling. The dimensions for Panel 2 are very close to actual airplane dimensions with a typical bay length-to-width-ratio of 3.

\subsection{Concluding Remarks}

The semi-analytical tool iBuck which is able to describe the local post-buckling behaviour of a stiffened cylindrical panel is presented.

The model is based on the Donnell type shell equations for thin, weakly curved shells that undergo large deflections. The stiffeners are perfectly bonded to the shell. For both the stringer and the frame webs additional degrees of freedom are included in the model. Thus the stiffeners are not "smeared" onto the skin.

Strongly local effects such as crippling cannot be described by iBuck. Since such effects do affect the global stiffness of the panel, they must be accounted for, for example, by reducing the flange bending stiffness.

For the load cases considered, good correspondence with non-linear FE-analyses was achieved. At the present time, iBuck is limited to local buckling and linear elastic material behaviour. In the future, both global buckling modes and elasticplastic material behaviour will be included in iBuck.

\section{Acknowledgement}

The tool TACO was developed within the project Design fundamentals for $3 D$ reinforced composites which was funded by the German state Lower Saxony and Airbus Germany. iBuck was developed as part of a sponsorship contract between Airbus Germany and DLR. All support is gratefully acknowledged. 


\section{References}

[1] Hightex Verstärkungsstrukturen GmbH, "Explanation of the TFP technology", http://www.hightex-dresden.de/.

[2] U. Kütemeier, P.J. Jörn, A.S. Herrmann, "Reverse Engineering für eine Bauteilfertigung in Tailored Fibre Placement-Bauweise“, DGLR-Tagung, Munich, 17-20 November, 2003.

[3] R. G. Cuntze, R. Deska, B. Szelinski, R. Jeltsch-Fricker, S. Meckbach, D. Huybrechts, J. Kopp, L. Kroll, S. Gollwitzer, R. Rackwitz, „Neue Bruchkriterien und Festigkeitsnachweise für unidirektionalen Faserkunststoffverbund unter mehrachsiger Beanspruchung - Modellbildung und Experimente“, Fortschrittsberichte VDI 5, 506, VDI Verlag, Düsseldorf, 1997.

[4] P. J. Crothers, K. Drechsler, D. Feltin, I. Herszberg, T. Kruckenberg, "Tailored fibre placement to minimise stress concentrations ", Composites Part A 28A, 28(7), 619-625, 1997.

[5] P. J. Crothers, K. Drechsler, D. Feltin, I. Herszberg, M. Bannister, "The design and application of Tailored Fibre Placement “, 11. International Conference on Composite Materials, Gold Coast, Australia, 1997.

[6] K. Gliesche, T. Hübner, H. Orawetz, "Application of the tailored fibre placement (TFP) process for a local reinforcement on an "open-hole" tension plate from carbon/epoxy laminates “, Composites Science and Technology, 63(1), 81-88, 2003.

[7] D. W. Kelly, M. W. Tosh, "Interpreting load paths and stress trajectories in elasticity ”, Engineering Computation, 17(2), 117-135, 2000.

[8] R. Li, D. Kelly, A. Crosky, "Strength improvement by fibre steering around a pin loaded hole ”, Composite Structures, 57(1-4), 377-383, 2002.

[9] C. Mattheck, A. Baumgartner, R. Kriechbaum, F. Walther, "Computational methods for the understanding of biological optimization”, Computational Materials Science, 1(3), 302-312, 1993.

[10] C. Mattheck, "Design in Nature ”, Interdisciplinary Science Reviews, 19(4), 298-314, 1994.

[11] P. Mattheij, K. Gliesche, D. Feltin, “Tailored Fiber Placement-Mechanical Properties and Application ”, Journal of Reinforced Plastics and Composites, 17(9), 1998.

[12] P. Mattheij, K. Gliesche, D. Feltin, “3D reinforced stitched carbon/epoxy laminates made by tailored fibre placement ”, Composites Part A, 31(6), 571581, 2000.

[13] P. Pederson, "Optimal Orientation of Anisotropic Materials, Optimal Distribution of Anisotropic Materials, Optimal Shape Design with Anisotropic Materials, Optimal Design for a Class of Nonlinear Elasticity ”, G.I.N. Rozvany (ed.), Optimization of Large Structural Systems, Vol. 2, 649-681, 1993.

[14] R. Kriechbaum, J. Schäfer, C. Mattheck, "CAIO (Computer aided internal optimization) A powerful method to optimize fiber arrangement in composite materials ", Proc. 1st European Conf. on Smart Structures and Materials, Glasgow, 281-284, 1992. 
[15] M. W. Tosh, D. W. Kelly, “On the design, manufacture and testing of trajectorial fibre steering for carbon fibre composite laminates ”, Composites Part A, 31(10), 1047-1060, 2000.

[16] M. W. Tosh, D. W. Kelly, "Fibre steering for a composite C-beam ", Composite Structures, 53(2), 133-141, 2001.

[17] C. Weimer, T. Preller, W. Mitschang, K. Drechsler, "Approach to net-shape preforming using textile technologies. Part I+II: edges and holes”, Composites Part A, 31(11), 1261-1277, 2000.

[18] K. Rohwer, R.Rolfes, "Calculating 3D stresses in layered composite plates and shells. Mechanics of Composite Materials” 1998;34: 491-500.

[19] J. Juhasz, R. Rolfes, K. Rohwer, „A new strength model for application of a physically based failure criterion to orthogonal 3D fiber reinforced plastics", Composites Science and Technology 61 (2001) 1821-1832

[20] S. Timoshenko, "Theory of Plates and Shells”, McGraw-Hill, New York, 1959.

[21] W. Flügge, “Statik und Dynamik der Schalen”, Springer-Verlag, 1981.

[22] K. Marguerre, "Die mittragende Breite der gedrückten Platte", Luftfahrtforschung, 14(3), 121-128, 1937.

[23] S. Levy, "Bending of Rectangular Plates with Large Deflections“, NACA Report No. 737

[24] O.F. Hughes, M. Ma, "Elastic Tripping Analysis of Asymmetrical Stiffeners”, Computers and Structures 60, 369-389, 1996.

[25] J.K. Paik, A.K. Thayamballi, S.K. Lee, S.J. Kang, "A Semi-Analytical Method for the Elastic-Plastic Large Deflection Analysis of Welded Steel or Aluminum Plating under Combined In-Plane and Lateral Pressure Loads”, Thin-Walled Structures 39, 125-152, 2001.

[26] E. Byklum, "A Simplified Method for Elastic Large Deflection Analysis of Plates and Stiffened Panels due to Local Buckling”, Thin-Walled Structures 40, 925-953, 2002.

[27] E. Byklum, “A Semi-Analytical Model for Global Buckling and Postbuckling Analysis of Stiffened Panels", Thin-Walled Structures 42, 701-717, 2004.

[28] E. Byklum, "Ultimate Strength Analysis of Stiffened Steel and Aluminium Panels Using Semi-Analytical Methods“, Ph.D. Thesis, Norwegian University of Science and Technology, 2002.

[29] E. Riks, "An Incremental Approach to the Solution of Snapping and Buckling Problems”, Int. J. Solids and Structures, 15 (1979), 529-551

[30] E. Steen, "Application of the Perturbation Method to Plate Buckling Problems”, Research Report in Mechanics 98-1, University of Oslo, 1998.

[31] R. Degenhardt, H. Klein, A. Kling, H. Temmen, R. Zimmermann, „Buckling and Post-Buckling Analysis of Shells under Quasi-Static and Dynamic Loads“, DLR (German Aerospace Center), 2002

[32] R. Rolfes, C. Hühne, A. Kling, H. Temmen, B. Geier, H. Klein, J. Teßmer, R. Zimmermann, „Advances in Computational Stability Analysis of ThinWalled Aerospace Structures Regarding Post-Buckling, Robust Design and Dynamic Loading“, $4^{\text {th }}$ International Conference on Thin-Walled Structures (ICTWS 2004), Loughborough, England, UK, 2004 